\title{
Introducing Collaborative Governance in Decentralized Land Administration and Management in South Africa: District Land Reform Committees Viewed through a 'System of Innovation' Lens
}

\author{
Evert Waeterloos
}

check for updates

Citation: Waeterloos, E. Introducing Collaborative Governance in Decentralized Land Administration and Management in South Africa: District Land Reform Committees Viewed through a 'System of Innovation' Lens. Land 2021, 10, 534. https://doi.org/10.3390/land10050534

Received: 31 March 2021

Accepted: 11 May 2021

Published: 18 May 2021

Publisher's Note: MDPI stays neutral with regard to jurisdictional claims in published maps and institutional affiliations.

Copyright: (C) 2021 by the author. Licensee MDPI, Basel, Switzerland. This article is an open access article distributed under the terms and conditions of the Creative Commons Attribution (CC BY) license (https:// creativecommons.org/licenses/by/ $4.0 /)$.
Institute of Development Policy (IOB), University of Antwerp, 2000 Antwerp, Belgium; evert.waeterloos@student.uantwerpen.be

\begin{abstract}
A Fit-for-Purpose (FFP) land administration system strives for a more flexible, inclusive, participatory, affordable, reliable, realistic, and scalable approach to land administration and management in developing countries. The FFP finds itself thus at the interface with the coordination and governance challenges of the mainstream promotion of democratic decentralization of the past decades in general, and collaborative systems for decentralized and participatory land governance in Africa, in particular. One recent example of such collaborative systems for decentralized land governance is the introduction in South Africa between 2015 and 2019 of District Land Reform Committees (DLRCs). We analyze this official experiment in collaborative land governance from a 'system of innovation' (SI) perspective. An adapted SI framework is developed and applied in three DLRCs. This study points out that for the innovation of collaboration to be effective, DLRCs require a firm operational and institutional backup. This is an important lead for the general discussion on inclusion, participation, and collaboration in FFP. We not only need these innovations to be well-supported and -resourced; they also require the explicit adoption of a systemic perspective in which various technical and social dimensions are interlinked.
\end{abstract}

Keywords: land governance reform; capacity development; Fit-for-Purpose land administration (FFP); institutional frameworks

\section{Introduction}

The past decade has seen the promotion of the concept of Fit-for-Purpose (FFP) land administration in response to challenges to security of access to land globally, especially in developing countries. The promoters of FFP land administration see, in addition to specific legal, institutional, and political factors, secure access to land especially hindered by the ambitions to adopt Western-style land administration systems that are too costly, time consuming and capacity demanding [1]. Rather than strictly abiding by advanced technical standards, a Fit-for-Purpose (FFP) land administration system aims to manage current land issues within a specific country or region through a more flexible, inclusive, participatory, affordable, reliable, realistic, and scalable approach [2]. Ho, Choudhury, Haran and Leshinsky [3] situate FFP, therefore, at the interface with the mainstream promotion of democratic decentralization of the past decades, and its challenges in India in terms of coordination and governance between the multiple levels and actors. These result especially in contested political authority, low local capacity, limited democratic dividends, and a lack of integration between new and existing land administration systems. They point out the need for collaborative governance to facilitate institutional integration and accountability and to allow the scaling of FFP to deliver also a 'fit-for-people' system that redistributes power and yields social justice. There has, indeed, been a resurgence of collaborative systems for decentralized and participatory land governance in Africa between state and non-state actors in the recent past, often to try and accommodate 
customary land governance in modern, land administration systems [4,5]. One recent example of such collaborative systems for decentralized land governance is the introduction in South Africa of District Land Reform Committees (DLRCs) between 2015 and 2019. In response to the slow and encumbered process of agrarian reform since 1994, these local multi-stakeholder platforms were introduced by the state in an attempt to improve local participation in land administration and management [6]. DLRCs were to identify farms for acquisition by government and candidates for farm allocation and advise on strategic support needs and land rights conflicts. However, from the beginning, DLRCs were not fully equipped with the required information, operational resources, skills, institutional clarity, accountability mechanisms or supervision [7]. In this contribution, we analyze the short-lived introduction of DLRCs specifically as an innovation for improved participation and collaboration in land administration and management. The experiences with this particular attempt at collaborative governance at the decentralized level are expected to provide pointers for the further conceptualization and implementation of Fit-for-Purpose land administration.

Our analysis will especially focus on the aspects of envisaged participation and collaborative governance in the FFP and its scaling-up. After briefly describing the complexity of South Africa's agrarian reform and decentralization programs, the roll-out of DLRCs in 2015 will be discussed. As the main innovative element of the DLRC initiative lies in promoting the collaboration of state and non-state actors toward joint proposals for land administration and management, we will first review the concept of collaborative governance. Since the focus in this article is on the innovation of promoting collaboration, the relevance of the 'system of innovation' (SI) approach for this undertaking is then explained. An adapted SI framework is developed for the structured yet simple assessment of collaborative governance as an innovation in three District Land Reform Committees. Using thus a fairly simplistic logic to describe complex (sub)system relations, information can be easily collected from within, analyzed and understood by both internal and external actors in terms of prevailing and aspired collaboration as well as priority support areas. These assessments of present collaboration opportunities and failures from a SI perspective in DLRCs do, in conclusion, lead to relevant pointers for the discussion of the systemic promotion of participation and collaborative governance in FFP in general.

\section{South Africa's Agrarian Reform: In Search of an Integrated and Inclusive Rural Economy}

\subsection{Decentralization and Coordination Challenges in Agrarian Reform}

Present day South Africa cannot be discussed outside of the country's specific historical path of colonial dispossession and Apartheid segregation. Since the Natives Land Act of 1913 and up until the first post-Apartheid elections in 1994, black people were formally excluded from secure access to land [8]. Fourteen million black people gathered in the former Bantustans and reserves-occupying only 13 percent of the country's area. The large majority of them engaged in small-scale or subsistence farming. Around 60,000 white farmers occupied 86 million hectares of privately owned land, or seventy percent of the country's total surface area. Post-Apartheid land reform policies begin with the 1994 Reconstruction and Development Programme (RDP), which saw land reform as 'the central and driving force of a programme of rural development' and set a specific target of redistributing 30 percent of the agricultural land by 1999 [9]. The 1997 White Paper on South African Land Policy [10] elaborates, in addition to the redistribution pillar, a tenure reform and restitution pillar. Under the restitution pillar, rights in land are meant to be restored to people who can prove that they were dispossessed of such rights after 19 June 1913 due to racist laws or policies. Tenure reform, on the other hand, has two distinct aspects: one deals with improving the security of tenure for those living on other people's land, primarily farm dwellers on commercial farms; the other aims at providing legally secure tenure for people living on communal land, primarily in the former Bantustans. With the slow and unsystematic progress of land reform since 1994, official statistics have accounted for both redistribution as well as restitution land transactions. Between 1994 
and 2016, the redistribution pillar had clocked 4.8 million hectares, while the restitution pillar was responsible for the transfer or compensation of 3.4 million hectares [11]. This total of 8.2 million hectares amounts to only 10 percent of the 80 million hectares of 'white agricultural land' that was reallocated through the publicly funded land reform program instead of the target of 30 percent.

It is against this background that in 2009, the Department of Rural Development and Land Reform (DRDLR) was created as the lead agency of agrarian transformation [12]. The DRDLR's Comprehensive Rural Development Programme (CRDP) of 2009 sought to facilitate integrated development through participatory approaches in partnership with all sectors of society. It was to deploy a three-pronged strategy of production and livelihoods support, land reform, and economic and social infrastructure development [13]. In 2012, South Africa's first National Development Plan (NDP) pleads similarly for an integrated and inclusive rural economy through the promotion of land reform, job creation and agricultural production. This requires support strategies tailored to local conditions and improved coordination between the national, provincial, and municipal government spheres [14-16]. The South African Constitution of 1996 created a government structure with three distinct but interdependent tiers: the national, provincial and local 'spheres' [17]. Some functions fall within a single sphere, while others are the responsibility of more than one sphere. The national sphere of government is exclusively responsible for functions that affect the country's security and economic unity, such as defense or land administration. It also formulates broad framework policies and has to monitor the implementation of these in or between lower spheres. The provincial sphere of government has the primary responsibility for public service delivery, for example, in education or agriculture. The sphere of municipal (Metro, District or Local) government is responsible for the delivery of basic services, such as water and sanitation. The way in which local development planning should find expression was set out in the Municipal Systems Act of 2000. The instrument of five-yearly Integrated Development Plans (IDPs) was introduced, which are supposed to integrate various actors and development interventions toward coordinated service delivery in a municipality. DRDLR - renamed as Department of Agriculture, Land Reform and Rural Development (DALRRD) in June 2019-was during the period of concern for this study (2015-2019), a national department responsible for land administration and management through its deconcentrated presence. Other government spheres involved in land reform and rural development were, for instance, provincial departments of agriculture or economic development as well as District and the subordinate Local Municipalities (DM and LM). Even in the Integrated Sustainable Rural Development Programme-the precursor to the CRDP, which was specifically dedicated to improved coordination and integration-municipal, provincial, and national authorities continued to fail in aligning their planning and implementation [15]. Despite a lack of technical capacity at the municipal level, the responsible provincial or national sector departments did not share information or participate in municipal planning processes. Together with discrepancies in planning and budgeting cycles between the different government spheres, such a non-cooperative disposition jeopardizes the efficacy of the intergovernmental set-up for agrarian reform. In addition, long-standing concerns exist about a renewed devolution of land governance and administration to traditional authorities in communal areas. Traditional authorities have argued that their roles in the governance of land have been usurped by the elected local government in the post-1994 era. More recent legislation, such as the Traditional Leadership and Governance Framework Act of 2003, the Traditional Courts Bill of 2017 and the Communal Land Tenure Bill of 2017, reallocate power to traditional leaders. It is feared that this may lead to further elite capture, insecurity of tenure, and marginalization of rural dwellers on, for instance, a class or gender basis [18]. Siddle and Koelble [19] plead, therefore, for a revision of the ambitious intergovernmental framework, a simplified task allocation in function of actual local government capacity, and possibly the recentralization of certain functions. Of particular interest to this research contribution is the launch 
by government of District Land Reform Committees (DLRCs) to address the fledgling coordination and decentralized implementation of agrarian reform [6].

\subsection{District Land Reform Committees as an Experiment in Decentralized Participatory Land Administration and Management}

In line with proposals from the 2011 Green Paper on Land Reform [20] and 2012 National Development Plan (NDP), DRDLR initiated in December 2015 the installation of District Land Reform Committees (DLRCs) throughout the country's 44 rural districts. DLRCs were set up at the district level as multi-stakeholder platforms to improve participation in decentralized land reform, governance, and management [6]. DLRCs would, in principle, consist of a diverse range of stakeholders, such as local representatives of line ministries, District Municipal officials or Councilors, agricultural interest groups, non-governmental organizations, and Traditional Leaders. DLRCs aimed for equal participation of local stakeholders in decisions on land acquisition and the implementation of centrally led policies. As such, DLRCs were purported to foster social mobilization and cohesion and build the capacity of rural citizens and local government officials. DLRCs were to identify farms for acquisition by government, identify candidates for farm allocation, and advise on strategic support needs and land rights conflicts. DRDLR was to provide technical and logistical support through a DLRC Secretariat and to the Beneficiary Selection Committee, a sub-committee of the DLRC for the identification of suitable candidates for land redistribution [6]. However, little clarity is provided in the policy on institutional issues, such as rules of decision making, safeguarding of inclusiveness of participants and land information, or the capacities required to fulfil all these functions by such a wide range of (non-) governmental representatives and their various interests.

A first, and, to our knowledge, only, systematic study thus far reviewed ten DLRCs in Eastern Cape, KwaZulu Natal, Limpopo and Western Cape provinces during their first year and a half of existence; they depict the challenges that these newly created spaces of participation and collaboration face [7]. Some of the challenges relate, for instance, to whether the target of an additional 20 percent of land to identify may also include private land transactions and how to coordinate with previous redistribution or restitution projects. Land redistributed by DLRCs will go to four mutually exclusive categories of previously disadvantaged black farmers: households with very limited (or no) access to land; small-scale farmers who sell part of their produce; medium-scale commercial farmers with the ability to expand; and finally, large scale or well-established commercial farmers with potential to expand. Every DLRC will need to strike a balance between economic production, social cohesion, and agrarian transformation. This also relates to other options of land use, which may not necessarily be agricultural but rather for human settlement or service provision. This requires substantive capacity building among DLRCs members and government officials, as they need to understand local land needs and uses and keep abreast of the evolving policy and legal context. However, at the time of the study, some DLRCs were not yet operational, while others met irregularly; they all suffered from a general dearth of public visibility, solid information on local land needs, and coordination and supervision from DRDLR [7]. The latter led to the DLRCs claim that they are performing unpaid work for government, which requires too much of their time and effort. The reviewers found that better information on local land needs and uses need to be gathered and disseminated, DRDLR should assume its coordinating role more prominently, attention should be paid to remuneration and members' skills, and the DLRCs must become more visible, accountable, and inclusive [7]. This recent experiment shows that decentralized platforms were created centrally with an ambit of land administration and management "for and by the people" without, however, fully equipping them with the required information, operational resources, skills, institutional clarity, accountability mechanisms or hands-on supervision [21]. Although only a future, country-wide evaluation of this experiment can provide an encompassing insight, this early assessment raises huge concerns about policy-driven institutional incoherencies in the DLRCs. This concern seems to be confirmed by the proposed replacement of DLRCs 
by more centrally led land allocation panels in a new draft of the National Policy for Beneficiary Selection and Land Allocation of 2020 [22]. Potential downside effects of such ineffective participation and collaboration by various (non-) governmental stakeholders in decentralized land administration and management are local elite capture, exclusion, and aggravated inequality, which may remain hidden from the eye of public accountability. It is evident that under these conditions, the innovation of DRLCs entails a huge risk of undermining rather than fostering social mobilization and cohesion as originally set out in the policy. The main objective of this contribution is to identify key characteristics of success and failure in the adoption of collaborative governance as an innovation in the DLRCs, and to formulate general recommendations for the promotion of participation and collaboration in FFP in general. For that purpose, we first need to define and operationalize the concept of collaborative governance in DLRCs from an innovation perspective.

\section{Conceptual Framework for the Study of the Introduction of Collaborative Governance in South Africa's DLRCs}

Globally, collaboration has been an important innovation trend in the public sector over the past decades [23]. Collaboration is understood as a subtype of coordination in which autonomous actors interact and negotiate (in) formally and jointly create rules and structures which involve shared norms and mutually beneficial interactions [24]. For clarity's sake, Emerson, Nabachi and Balogh [25] add that this is to carry out a public purpose that could not otherwise be accomplished by the actors individually. Achieving shared and interdependent collaboration implies a dynamic synergetic process characterized by multiple viewpoints, contradictions, and unintended outcomes [23]. The recent promotion of collaborative governance proves, however, to be highly complex and context-dependent. Not in the least since its theoretical and empirical development is informed by multiple disciplines, theories, and practices of which, for instance, Emerson, Nabachi and Balogh [25] provide a succinct overview.

\subsection{Counting Collaboration on one Hand?}

To approach the DLRCs from the perspective of collaborative governance as an innovation, we first revisit Ansell and Gash's [26] review of more than 130 studies of collaborative governance, which they understand as the public sector's strategy to formally incorporate non-state stakeholders into consensus-oriented decision-making processes. The five critical variables of collaborative governance that they retain are facilitative leadership, institutional design, face-to-face dialogue, trust building, and commitment and shared understanding. In this, they pay particular attention to incentives to participate, power and resource imbalances, and prior history of conflict or cooperation. In a broader take on collaboration in such settings, Thomson and Perry [24] do not limit their interest to state strategies of formal engagement with other stakeholders only. They define collaboration as a voluntary alignment process between actors in general with shared norms and mutually beneficial interaction. From their extensive multi-disciplinary literature review, they retain five similar but wider-ranging core dimensions: governance, administration, autonomy, mutuality, and social capital. The combination of these dimensions articulates collaborative action; in other words, ideally, strong collaboration requires a full hand made up of these five dimensions or fingers. Since the main innovative element of the DLRC initiative lies in promoting the collaboration of various (non-) governmental actors toward joint proposals for land administration and management to be submitted by the DLRC to the central ministerial level for approval, we will, in the first instance, base our analysis on the broader conceptual understanding of collaboration in se in the promotion of collaborative governance. To that effect, the five collaboration fingers will be discussed here and, where relevant, complemented with elements from Ansell and Gash's [26] collaborative governance model.

The first dimension of collaboration, governance, is characterized by participative decision making, shared power arrangements and joint problem solving [24]. Therefore, a reputation of trustworthiness, face-to-face communication, and the creation of an ethic 
of collaboration, while building the respective reputations, benefit collaboration. This is corroborated by Ansell and Gash [26] who highlight the critical role of the institutional set-up, shared ownership of process, face-to-face dialogue, and trust building. The second dimension, administration, needs to be adapted to horizontal and symmetrical relationships between non-hierarchical autonomous units. Additional complexity surfaces, as autonomous partners may play different administrative roles simultaneously, such as those of convener, advocate, technical assistance, funder, facilitator, and others [24]. Thirdly, parties bear at least a dual identity: their own distinct organizational identity and interests, and the collaborative ones. When a balance can be established between individual and collective interests, there is ample evidence that collaboration can yield highly satisfying results. This is the third finger of autonomy - the ability to defend and pursue individual stakeholders' interests within the collaborative venture. Organizations that collaborate must, in the fourth instance, experience mutuality, which includes beneficial interdependencies based on differing or shared interests. Shared interests may derive from homogeneity in mission or can also be informed by meta-issues, such as humanitarian crises. Collaboration based on differing interests or complementarities occurs when one party has unique resources, such as skills or funds, which another party needs. Ansell and Gash's model [26] is heavily biased toward this fourth dimension. For instance, the starting conditions of power-resource-knowledge asymmetries and incentives for and constraints on participation fall within the realm of mutuality. In particular, recognition of interdependence, openness to explore common values, mutual gains and common problem definitions highlight the importance of mutuality to the formal collaboration between state and non-state actors. The fifth finger on the collaboration hand refers to the extent of trust and reciprocity. Often, individual partners only dare to collaborate if other partners demonstrate a similar willingness. This 'tit-for-tat' reciprocity is based on the perceived degree of obligation; partners are willing to initially bear disproportional costs because they expect the others to act fairly and equalize the distribution of costs and benefits over time. Closely related to reciprocity is trust, which is the belief that the other partners will be honest, will try to stick to commitments, and will not take excessive advantage of the other. Trust reduces complexity and transaction costs in collaboration, and as collaborative partners interact and build reputations for trustworthy behavior over time, they may move away from tit-for-tat reciprocity to longer-term commitments [24].

When in the context of decentralization, coordination - of which collaboration is a subtype - is ineffective, various coordination gaps may appear. Charbitt [27] distinguishes seven such gaps in decentralized contexts: information, capacity, fiscal, policy, administrative, objective and accountability gaps. An information gap is characterized by information asymmetries between levels of government and is included in the governance finger of the collaboration hand, which considers the degree of shared power arrangements and joint problem solving as based, among others, on sharing information [24]. An administrative gap occurs when the administrative scale for policy making and implementation is not in line with its functional reach. In turn, capacity gaps may arise when there is a lack of human, knowledge, or infrastructural resources to carry out tasks at any of the government levels. The fiscal gap is represented by the difference between subnational revenues or financial resources and the budget required to implement the identified development strategies [27]. These three gaps are dealt with in Thomson and Perry's [24] administration dimension, which captures the different administrative roles that partners simultaneously may play, such as convening, technical assistance or funding. Charbitt's policy gaps result when central line ministries take a purely vertical or silo approach, while subnational governments are thought to be best placed to customize complementarities between policy fields. The objective gap refers to different rationalities among national or subnational policy makers, which create obstacles for adopting convergent strategies. These two gaps are fully covered by the fingers of autonomy and mutuality on the collaboration hand. Collaborative actors must experience mutually beneficial interdependencies and only such perceived mutuality can enable a collaboration in which stakeholders defend and pur- 
sue common interests without loss to their own autonomous interests [24]. Finally, an accountability gap surfaces when the transparency of practices across different levels of government falls short or the integrity of policy makers is questioned. The success factors of trust and reciprocity on the collaboration hand cover this aspect. Thomson and Perry's five-fingered analytical framework of collaboration appears, thus, sufficiently robust to heed coordination risks specific to multi-level interactions as pointed out by Charbitt [27]. Now that we have elaborated the conceptual understanding of collaboration in the new collaborative governance set-up of DLRCs, we turn our attention to framing its introduction as an innovation.

\subsection{A System of Innovation Framework for Collaborative Governance}

The study of specific innovations as part of a wider system has, since the late eighties, received attention through the so-called 'system of innovation' approach. The neo-classical perspective on innovation, which deems that technical change stems from an isolated profit-maximizing agent, may overlook important interrelations. For instance, many actors involved in research and development, such as universities and public research institutions, are not primarily profit-seeking. The legal context also plays a significant role in shaping innovation opportunities and possibilities [28]. In the late 1980s, the 'system of innovation (SI)' approach emerged to focus on the influence of national policies and institutions on innovations. Here, innovation is seen as a non-linear process in which actors interact with a manifold of other organizations, such as research institutes or financial organizations, and institutions, such as laws, regulations, cultures, or codes of conduct. These interactions are influenced by the institutional set-up of society as well as capabilities of the individual actors in the system $[28,29]$. According to SI, for innovations to be successful, interactions between actors need to take place, rules of the game have to be observed, the evolutionary process has to function, and actors need to have innovation capabilities. If these functions are ineffective, system failures appear [30]. Klein Woolthuis, Lankhuizen and Gilsing [29] propose a framework of system failures, which distinguishes between system failures and the actors involved. These actors-policy makers, customers, or firms-are not only seen to (co-) create products and technologies, but the actual institutional framework in which they function as well. Setting system failures against actors allows a clearer attribution of (mal) functioning: a system network failure may, for instance, be differentiated in terms of a lack of cooperation with either technologically complementary firms (producers) or innovation-stimulating market parties (consumer-oriented). In the systems-failure framework, infrastructural failures pertain to failures in the physical infrastructure, such as accommodation or information technology. When institutions fail to institutionally regulate economic behavior and interaction, they may hinder innovation. Hard institutional failures refer to the formal institutional mechanisms, such as technical standards or health and safety regulations. Soft institutional failures refer to the implicit rules of the game and include social norms and values, such as entrepreneurship. Interaction failures can surface when there is either too much or too little interaction. Intensive cooperation between actors can be very productive as a source of creative problem solving and capacity sharing. However, strong cooperative relationships may also lead to myopia and inertia, where parties mainly focus on themselves and on what they do well. As a result, actors may be locked into existing technological trajectories. On the other hand, if certain actors dominate, they may lock in others into their ways of doing things due to, for instance, a lack of alternative partners. Such weak network failures may lead to the underutilization of opportunities for learning and innovation. Finally, in the case of capability failure, actors may simply lack the individual competences, capacity, or resources for effective innovation and interaction. In short, this framework points out where an innovation system failure will likely occur, differentiates between distinct types of failure, and enables the evaluation of how effectively failures have been addressed [29].

The system failure framework of Klein Woolthuis, Lankhuizen and Gilsing [29] hones in on infrastructural, institutional, interaction and capabilities risks during innovations. 
Where may such SI potential failures then appear in the five finger-model of collaboration of Thompson and Perry [24]? Institutional failures in collaborative governance as an innovation may be linked to ineffective legal and regulatory frameworks or norms and values, and be situated in the governance finger. In managing voluntary collaboration between autonomous actors, the key is the right combination of administrative capacity to coordinate and elements of hierarchy and social capacity to build relationships [24]. In terms of the SI, this administration finger requires hard infrastructural resources, such as meeting facilities, as well as soft administrative infrastructure, such as operational and human resources. Interactions between various collaboration candidates can hamper new forms of collaboration if shaped by centripetal or a lack of centrifugal forces in the case of respectively strong or weak network failures. In addition, Charbitt [27] stresses the risk of information failure in a multi-level governance set-up. It is, therefore, critical to include in the proposed SI framework to assess DLRCs the existing and preferred levels of informational interaction between stakeholders, including between the central and local level. Prior interactions of cooperation or conflict and the crucial role of leadership herein are suggested by Ansell and Gash's [26] to determine the range of collaboration opportunities. Hence, asymmetrical power distribution, prior cooperation or antagonism and the facilitating role of leaders are added in the proposed SI under the interaction dimension. Finally, SI's attention to individual capabilities for innovation is further specified for collaboration —informed by Thomson and Perry [24] and Ansell and Gash [26] —as the ability to pursue autonomy and mutuality and to trust and reciprocate in a practical, as opposed to a normative, way. Autonomy and mutuality are operationalized as the ability to defend and pursue own interests and common interests, respectively. Reciprocity or tit-for-tat commitment as proposed by Thomson and Perry [24] is operationalized as actual working together by providing committed, obligatory inputs. Trust is then measured by whether actors in a collaboration setting are thought to also provide non-obligatory, voluntary, or additional inputs (in future) or are able to make proactive use of the environment for the common goal (going the extra mile). It should be noted that mutuality, in principle, not only features in the capability subsystem; partners who acknowledge shared benefits may forge common problem definitions and identification of common values. Failing to translate such mutuality into laws, regulations, norms, or values are either hard or soft institutional failures, which may pose a risk to innovation. Thus, adapting Klein Woolthuis, Lankhuizen and Gilsing's [29] generic system failure framework of innovation to the multiple dimensions of collaborative governance $[24,26]$, specifically in a multi-level setting [27], intends to yield a more complete framework for the systematic analysis of collaborative governance as an innovation in South Africa's DLRCs.

The SI framework for collaborative governance that we elaborate in Figure 1 draws on Klein Woolthuis, Lankhuizen and Gilsing's [29] framework. However, the four subsystemsfailure in infrastructure to perform the key administration function of collaboration in a multi-level governance set-up; institutional failure; interaction failure and capability failure-have been retained as dimensions, and not necessarily as failures as such. Further qualifications (e.g., administrative infrastructure; information exchange between central and local level) and specifications (e.g., leadership; power balances; past cooperation and conflicts) have been added, based on the above-summarized literature review. The resulting SI framework for collaborative governance can, in line with the metaphor of the five-fingered hand of collaboration, be represented in a more mechanistic way by a four-wheel drive car. For the car as an entity or system to move, each wheel requires an individual 'drivetrain' or subsystem to transfer power to the wheels. Each drivetrain is compiled of different components, resulting in different forces being transferred to the wheels. The speed and comfort with which the car can cobble over difficult terrain depends on the interrelation and synchronization between the distinct subsystems. Viewed from above, and with one axis representing the original system's structural and the other axis the actor dimension, the collaboration car and its four drivetrains appear as follows. 


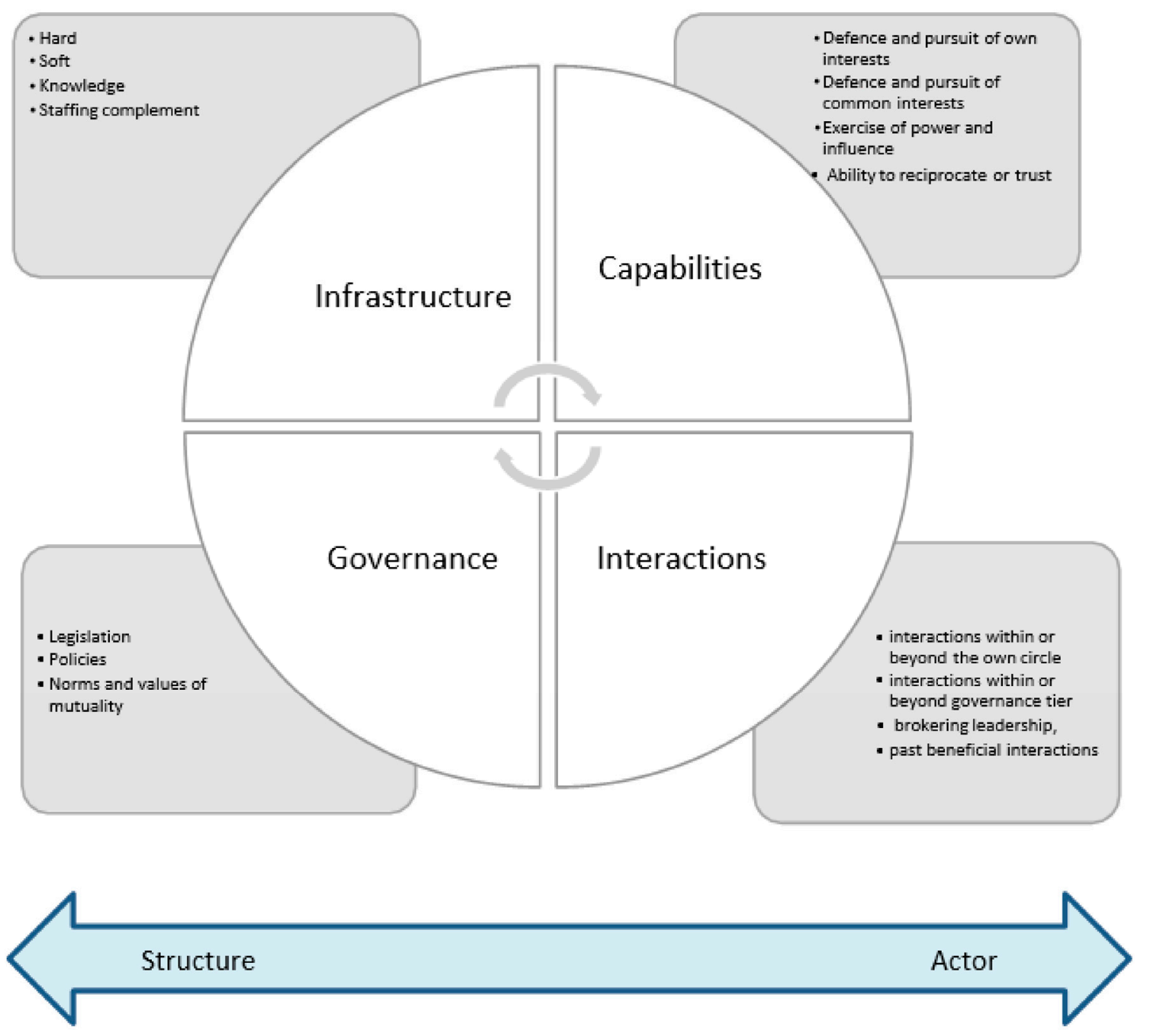

Figure 1. SI Framework for Collaborative Governance.

The four drivetrains-infrastructure, capabilities, governance, and interactions- represent the subsystems of the SI framework for collaborative governance; their relevant components are listed in each wheel and represent the collaboration-specific characteristics identified in the literature. Moreover, when incorporating an assessment of not only the actual but also of aspired levels of collaboration, this new framework not only allows to determine which systemic failures of collaboration prevail, but also to what extent. Through a comparison between the actual and the preferred scenario of collaboration, it allows to analyze, in addition, how these system failures may be resolved. Such a comparison facilitates a regular iterative assessment of actual progress toward innovation as promoted by the SI perspective. In that sense, it not only turns into a framework that scans for the system's opportunities for collaboration rather than merely its failures, but, more so, it has the potential to monitor progress in resolving the most relevant system failures by measuring ongoing discrepancies between the actual and preferred performance for each collaboration dimension. The important subsystems of collaboration and their components are a range of hard and soft infrastructural features related to administration for collaboration: legal and policy frameworks, norms and values toward shared outcomes; interactions within or beyond the own circle or governance level, brokering leadership, and past beneficial interactions; and capabilities involving both the defense and pursuance of own as well as common interests, the exercise of power and influence, and the ability to reciprocate or trust. This proposed framework is specified below for three DLRC case studies in South Africa. 


\section{Collaborative Governance in District Land Reform Committees: How Far (To Go)? \\ 4.1. Case Study Rationale and Methodology}

This collaboration case study applies the developed SI framework for collaborative governance in three DLRCs-Chris Hani, Joe Gqabi and Sarah Baartman-in the Eastern Cape province. These three DLRCs are selected from the 2017 review of ten DLRCs on the basis of their operationality, availability of encompassing plans for rural development, and openness to research [7]. For purposes of information gathering, official members of the three DLRCs were interviewed between February and April 2019. The DLRCs of Sara Baartman and Joe Gqabi consisted each of 14 members with known contact details, while only 10 DLRC members could be traced in the Chris Hani DLRC, bringing the total to 38 governmental and non-governmental respondents. They were asked to individually assess how collaboration is actually undertaken, supported, or impacted upon in each of the subsystems and dimensions identified as conducive for collaboration. The SI framework was adjusted to the tasks and composition of the DLRCs (see Table 1). For instance, infrastructure refers to the meeting venue, facilities, and IT equipment and stationery to support the new DLRCs; financial resources refer to sitting or travel allowances, resources for site visits, and payment of support staff; human resources refer to the number, efficiency, and knowledge of DRDLR staff and/or members of DLRC who provide operational or technical support to DLRC. Governance is covered by the knowledge that the members of DLRCs have of the laws and legal regulations on DLRCs and on operational guidelines, policies, and strategies, as well as the norms and values of members of DLRC to make decisions which promote interests and objectives shared by all members. Interactions are captured by the assessment regarding whether the information on DLRC matters is circulated and exchanged between stakeholders at the local as well as the central level, or rather only at the national or provincial level; whether members of DLRC exchange questions, ideas and proposals with stakeholders other than DLRC members or mostly only among themselves; if members of DLRC have worked well together with each other in the past; and whether severe power imbalances are noticed when it comes to decision making in the DLRC, as well as whether the leadership of the DLRC supports the decision making in the DLRC in such a manner that members of DLRC are able to come to shared, joint decisions. Capabilities indicate whether members of the DLRC are able to defend their own interests and those of the groups they represent; whether or not all members of the DLRC defend the common interests; and whether members of the DLRC fulfil the duties they are legally obliged to fulfil, do willingly extra tasks when asked to do, or take the initiative to fulfil additional tasks in addition to their standard duties (going the extra mile). Subsequently, respondents assessed the degree of contribution that is preferred or required to render the collaboration in that subsystem or dimension successful. Assessment scores were solicited in ten equal percentage intervals, with 0 percent being the lowest and 100 percent the highest assessment score. Such intervals facilitate the gathering of assessments by providing a limited number of categories for scoring, yet still allow a meaningful use and interpretation of the scores on a continuum. The various dimensions' actual scores are expressed as a percentage of preferable scores so that each and every dimension-even the ones with a degree of preferability of less than 100-is standardized for the purpose of comparison. The standardized assessments of the actual vis-à-vis preferred status thus reveal existing opportunities (high scores) and gaps (low scores) for collaboration as an innovation. In order to identify possible external support mechanisms to revealed systemic collaboration failures, an additional question was put to the DLRC members. This question relates to the role of governments or organizations from outside South Africa who may be willing to assist the DLRCs to improve their operations in land administration and management in line with South Africa's legislation and policies. Members were asked to highlight the five most important areas where such external support to collaboration may contribute most significantly in their DLRC. Below is an outline of the developed system framework, while the full questionnaire is attached in Appendix A. 
Table 1. SI framework for collaboration in DLRCs.

\section{Collaboration Dimensions}

Individual DLRC Members' Assessments of Actual and Preferred Collaboration

Administration: convening, advocating, technical assistance, funder, facilitator ...

Physical infrastructure/resources: Secretariat and meeting facilities

Actual: $0-100 \%$

Preferred: $0-100 \%$

Human resources: number

Actual: $0-100 \%$

Preferred: $0-100 \%$

Human resources: competency

Actual: $0-100 \%$

Preferred: $0-100 \%$

Actual: $0-100 \%$

Operational resources: financial means for, e.g., sitting, accommodation and Preferred: $0-100 \%$ subsistence allowances, transport, site and exchange visits Governance: participative decision making, shared power arrangements and problem solving

Legal framework

Policy framework

Norms, values towards shared outcomes (mutuality)

Network interactions

Dominant stakeholders exchange predominantly amongst themselves to elaborate their expertise further (centripetal)

Dominant stakeholders engage with new stakeholders to explore new ideas and methods (centrifugal)

Information exchange between central level stakeholders

Information exchange between central and local level stakeholders

Stakeholders have engaged productively with each other in the past

$$
\text { Leadership }
$$

Actual: $0-100 \%$

Preferred: $0-100 \%$

Actual: $0-100 \%$

Preferred: $0-100 \%$

Actual: $0-100 \%$

Preferred: $0-100 \%$

\section{Capabilities}

\section{Ability to defend and pursue own interests}

Ability to defend and pursue common interests

Severe imbalances in power between the stakeholders are to be expected

Actual working together by providing committed/obligatory inputs

Actual working together by providing non-obligatory, voluntary or additional inputs

Making proactive and maximal use of the environment/situation for the common goal (going the extra mile)
Actual: 0-100\%

Preferred: 0-100\%

Actual: $0-100 \%$

Preferred: 0-100\%

Actual: $0-00 \%$

Preferred: 0-100\%

Actual: $0-100 \%$

Preferred: 0-100\%

0-100\%

Actual: 0-100\%

Preferred: $0-100 \%$

Actual: 0-100\%

Preferred: 0-100\%

Actual: $0-100 \%$

Preferred: 0-100\%

$0-100 \%$

Actual: $0-100 \%$

Preferred: $0-100 \%$

Actual: 0-100\%

Preferred: 0-100\%

Actual: 0-100\%

Preferred: $0-100 \%$

\subsection{Systemic Failures and Opportunities in the Innovation of Collaborative Governance}

In terms of standardized assessments of the present vis-à-vis preferred situation, the three DLRCs demonstrate clear, common, but also very specific, patterns. Overall, opportunities for collaboration as an innovation to work are assessed fairly high in the present rural system with an average score of 61.68 percent across the three DLRCs and the four subsystems of administration, governance, networking, and capabilities (Table 2). The composite 
score of system opportunities of collaboration is the mere sum of DLRCs scores in the four subsystems. The opportunities are commonly discerned to be lowest in the subsystem of administration (almost $48 \%$ ) and highest in the subsystem of governance $(67.76 \%)$. The capabilities and networking dimensions score in between with respectively almost $64.46 \%$ and $66.52 \%$. The linear tradition in public administration and management analysis is expressed very clearly in this SI framework in the assumption of simple additivity of the composite score of (sub) system opportunities of collaboration. The idea that decision making and management in public policy and public administration are complex should, however, receive far more attention in operational research (see further) [31].

Table 2. (Sub) systems and opportunities of collaboration in DLRCs (average standardized assessment score in \%).

\begin{tabular}{cccccc}
\hline DLRC & $\begin{array}{c}\text { Administrative } \\
\text { Infrastructure }\end{array}$ & Governance & Networking & Capabilities & $\begin{array}{c}\text { System Opportunities of } \\
\text { Collaboration }\end{array}$ \\
\hline Chris Hani & 48.63 & 59.67 & 65.67 & 62.79 & 59.19 \\
\hline Joe Gqabi & 47.32 & 75.71 & 75.89 & 69.32 & 67.06 \\
\hline Sarah Baartman & 48.20 & 65.60 & 57.72 & 60.78 & 58.08 \\
\hline Total & 47.99 & 67.76 & 66.52 & 64.46 & 61.68 \\
\hline
\end{tabular}

The weakest administrative opportunities for the introduction of collaboration (Table 3) are identified in the financial resources available, for instance, for sitting and travel allowances or running costs of the secretariats (Q2 26.44\%), as well as the human resources (Q3 number of staff $49.96 \%$ ) who provide operational or technical support to DLRCs and their efficiency and skills profile (Q4 53.60\%). The least systemic failure in the administrative drivetrain is located in the physical resources and infrastructure, such as the meeting venue and facilities or IT equipment, which do score reasonably (Q1 61.95\%). The DLRC under the most financial pressure to meet its obligation and expectations is Joe Gqabi, which assesses its actual financial performance as 20 percent of its preferred profile (Q2). The Sarah Baartman DLRC is in a relatively better position, having reached 35.70 percent of its preferred financial resourcing position.

Table 3. Administrative infrastructure (average standardized assessment score in \%).

\begin{tabular}{cccccr}
\hline DLRC & Q1 & Q2 & Q3 & Q4 & Administrat. Infrastructure \\
\hline Chris Hani & 62.00 & 22.50 & 53.00 & 57.00 & 48.63 \\
\hline Joe Gqabi & 68.21 & 20.00 & 50.00 & 51.07 & 47.32 \\
\hline $\begin{array}{c}\text { Sarah } \\
\text { Baartman }\end{array}$ & 55.65 & 35.70 & 47.76 & 53.70 & 48.20 \\
\hline Total & 61.95 & 26.44 & 49.96 & 53.60 & 47.99 \\
\hline
\end{tabular}

The more conducive scores for collaboration are found for capabilities, networking, and governance. In terms of capabilities, Table 4 reports that all members of the DLRC fulfil additional tasks in addition to their standard duties (going the extra mile) (Q19), receiving the highest affirmation of 81.39 percent, followed by the assessment that all members of the DLRC willingly do extra tasks in addition to their standard duties when asked to do so (Q18 81.13\%). However, there is less of a convincing assessment in both capability factors in Sara Baartman (73.05\% and 73.06\%). Similar scores are given to the statement that members are able to defend their own groups' interests in the DLRCs (Q15 80.34\%), especially in Joe Gqabi (88.93\%). Whether members of the DLRC defend the common interests of all people of the district $(\mathrm{Q} 16)$ is the most varied factor, ranging from a high of 87.50 percent in Joe Gqabi to a lower 64 in Chris Hani. Except in Joe Gqabi (Q13 53.57\%), members of DLRC consider themselves to be able to exercise fairly equal levels of power and influence (a rather low 35 and 41 percent assessment score of unequal power distribution in Chris Hani and Sarah Baartman). While Thomson and Perry [24] acknowledge that beneficial 
interdependencies based on differing interests may feed collaboration where one party needs unique resources from the other, power imbalances may also lead to manipulation of weaker actors [26]. These conditions do not seem to prevail here, as DLRC members find that they are quite able to defend their own groups' interests. This is even more so in the Joe Gqabi DLRC, which displays the most unequal power distribution. The rather low assessments of actual power imbalances as well as the members' firm interest representation capacity do not justify attributing a strong negative influence on collaboration to power imbalances in the DLRCs under review. In the absence of any indication from the literature on how to objectively express the magnitude of the reported negative influence, a rough estimate has been resorted to here. When proposing an intuitive course scale of 100 percent for a full-fledged, strong influence, 75 strong, 50 mild, 25 very mild and 0 no effect, a counter-collaboration vector of 25 percent seems adequate in the case of the three DLRCs because of the above-explained indications of inequality. This means that the imbalance of power is treated as a negative force in the composite of capabilities, but only up to 25 percent of its assessed value. This turns, for instance, the overall average score of Q13 of 43.42 percent into a vector of -10.86 percent (Q13VECTR). As coarse as this approach may be, it does provide a first way to discount the negative influence that power imbalances may have on collaboration while awaiting further experimentation. In the case of the three DLRCs, it levels off some of the high-end self-assessment scores on, for instance, going the extra mile or defending the common interests in the most 'capable' DLRC of Joe Gqabi, which, coincidentally, also knows the highest power inequality (see further). Discounting the negative effect of power imbalances-even as coarsely done as it is here-yields a more consistent pattern across the three DLRCs of composite capabilities (CAPABILITIES), which center around the overall average of 64.46 percent.

Table 4. Capabilities (average standardized assessment score in \%).

\begin{tabular}{cccccccccc}
\hline DLRC & Q13 & Q13VECTR & Q15 & Q16 & Q17 & Q18 & Q19 & CAPABILITIES \\
\hline Chris Hani & 41.00 & 10.25 & 75.00 & 64.00 & 82.00 & 83.00 & 83.00 & 62.79 \\
\hline Joe Gqabi & 53.57 & 13.39 & 88.93 & 87.50 & 76.43 & 87.86 & 88.57 & 69.32 \\
\hline Sarah Baartman & 35.00 & 8.75 & 75.56 & 75.18 & 76.61 & 73.06 & 73.05 & 60.78 & 64.46 \\
\hline Total & 43.42 & 10.86 & 80.34 & 76.78 & 77.96 & 81.13 & 81.39 & \\
\hline
\end{tabular}

The third subsystem of actual interactions and networking within the DLRCs appears promising, churning out assessment scores ranging between 42 and 81.84 percent, on average (Table 5). The lowest score is found in the circulation of information among stakeholders at the district level (Q8 42.00\%). This score has been constructed by deducting the originally obtained response on reserving information, especially at the national or provincial level, rather than circulating among local stakeholders (original Q8) from a justifiable ideal preference score of 100 percent for local circulation of information. This deducted score is in line with the fairly low exchange of information between stakeholders at the local and central level (Q7 57.64\%), while leadership toward shared decision making appears to be already quite present (Q14 81.84\%). Big variations can be observed in reserving information among stakeholders at the national or provincial level rather than at the district level, with Sarah Baartman suffering most from this as opposed to Joe Gqabi (respective constructed Q8 scores of $28.71 \%$ and $54.29 \%$ ). Previous positive cooperation experiences before the existence of DLRCs also vary widely from a high Q12 score of 90 percent to one of only 55 in Sarah Baartman. Clearly, social capital differs from context and locality. 
Table 5. Network interactions (average standardized assessment score in \%).

\begin{tabular}{cccccccc}
\hline DLRC & Q7 & Q8 (Constructed) & Q10 & Q11 & Q12 & Q14 & NETWORK \\
\hline Chris Hani & 59.50 & 43.00 & 62.50 & 70.50 & 82.50 & 76.00 & 65.67 \\
\hline Joe Gqabi & 61.43 & 54.29 & 78.57 & 84.64 & 90.00 & 86.43 & 75.89 \\
\hline Sarah Baartman & 52.52 & 28.71 & 59.84 & 68.83 & 55.00 & 81.43 & 57.72 \\
\hline Total & 57.64 & 42.00 & 67.44 & 75.10 & 75.13 & 81.84 & 66.52 \\
\hline
\end{tabular}

One subsystem that is noteworthy for the introduction of collaboration is the governance drivetrain (Table 6), which covers the legislation (Q5), guidelines, policies and strategies pertaining to DLRCs (Q6), and the prevailing norms and values toward mutuality-the promotion of shared interests and objectives (Q9). It is the latter that is reported to be most prevalent (average of $77.89 \%$ ), but with high variation between, for instance, Sara Baartman, which reports a low score on mutuality $(70.36 \%)$, and Joe Gqabi, where members of the DLRC assess their pursuit of shared goals to be quite satisfactory (more than $87 \%$ of the preferred score Q9). This is combined with the highest score for knowledge among members of the legal (Q5) and regulatory (Q6) frameworks that govern the DLRCs, thus making the DLRC of Joe Gqabi stand out as the most promising one for collaboration in governance terms. The Chris Hani DLRC, on the other hand, displays the lowest knowledge of such legal (Q5 44\%), regulatory and strategic frameworks (Q6 59.50\%) and overall governance opportunities (GOVERNANCE 59.67\%), yet their members seem to perform well in pursuing a joint agenda of shared objectives (Q9 75.50\%).

Table 6. Governance (average standardized assessment score in \%).

\begin{tabular}{ccccc}
\hline DLRC & Q5 & Q6 & Q9 & GOVERNANCE \\
\hline Chris Hani & 44.00 & 59.50 & 75.50 & 59.67 \\
\hline Joe Gqabi & 68.21 & 71.79 & 87.14 & 75.71 \\
\hline Sarah Baartman & 60.71 & 65.71 & 70.36 & 65.60 \\
\hline Total & 59.08 & 66.32 & 77.89 & 67.76 \\
\hline
\end{tabular}

\subsection{Priorities for the Promotion of Collaboration in DLRCS}

Bringing it all together is the composite score of system opportunities of collaboration (Table 2). By simply adding the DLRCs scores on the four subsystems, a differentiation can be made between DLRCs in terms of overall opportunity for the successful introduction of collaboration. The DLRC of Joe Gqabi scores the best for all systemic opportunities, except for administrative infrastructure. The SI framework, thus, proposes Joe Gqabi as the best candidate for the successful promotion of collaboration, yet warns for slight constraints in the administrative infrastructure in comparison with the other DLRCs. This result underlines the simplicity of the assumption of mere linear additivity of the four subsystems at this stage in the development of the SI framework. Despite subscribing to the idea of collaboration as non-linear and emergent, Thomson and Perry's [24] five-dimensional model falls short in operationalizing this beyond the concept of a covariant model in which variations across dimensions influence each other. They are, for instance, not able to point at specific critical levels for any of the dimensions. Interactions within complex public administration system set-ups often yield unexpected and unpredictable outcomes, which complexity approaches try to explain by factors of non-linearity, emergence, or self-governance [32]. The SI framework under development does, for instance, not take into account the constraining or accelerating effects that investment in the administrative structure may have on the other three subsystems. This is particularly relevant when discussing the DLRC of Joe Gqabi, the most likely candidate for a successful introduction of collaboration as an innovation. It is also the DLRC under the most financial pressure to meet its obligations and expectations since it assesses its actual financial performance as 20 percent of its preferred profile (Q2) 
(Table 3). The DLRC also scores highest for knowledge of the legal (Q5) and regulatory frameworks (Q6), previous positive cooperation experiences before the existence of DLRCs (Q12 90\%), but also for power imbalances (Q13 53.57\%). In terms of some of these complex interrelations, the question then begs whether, in the likely event of prolonged absence of sufficient investment in administrative infrastructure, Joe Gqabi's development potential for collaboration may not reverse drastically toward elite capture or disinterest, for instance? At this stage, the proposed SI framework cannot yet provide a clear-cut response to these concerns of complexity.

The analysis of differences between actual and preferred assessment scores-each with a range between 0 and 100-does, however, reveal which are the most urgent discrepancies that need to be addressed (Table 7). The financial resource discrepancy (Q2STD) is overall the least satisfactory, clocking a difference between actual and preferred scores of 73.10 percent; this difference runs in Joe Gqabi up to 80. High discrepancies of almost 50 percent can be observed for the number of human resources (Q3STD) and their quality (Q4STD), as well as the lack of information flow to the district level (Q8STD), the latter again especially in Joe Gqabi (54.29\%). The least discrepancy is found in members fulfilling their duties with additional efforts put in the exercise (less than 22\% for Q17STD, Q18STD and Q19STD), making decisions for the common interest (Q9STD), roles of leadership (Q14STD) and members being able to defend their interests (Q15STD). Here, again, it is Joe Gqabi that scores most positively with the fewest differences between the actually observed and preferred situations for most variables.

Table 7. Discrepancies between actual and preferred situation (average \%).

\begin{tabular}{ccccccccccc}
\hline DLRC & Q1STD & Q2STD & Q3STD & Q4STD & Q5STD & Q6STD & Q7STD & Q8STD & Q9STD & Q10STD \\
\hline $\begin{array}{c}\text { Sarah } \\
\text { Baartman }\end{array}$ & -42.14 & -61.79 & -51.01 & -45.07 & -39.29 & -34.29 & -46.07 & -43.57 & -29.64 & -38.21 \\
\hline Joe Gqabi & -31.79 & -80.00 & -50.00 & -48.93 & -31.79 & -28.21 & -38.57 & -54.29 & -12.86 & -21.43 \\
\hline Chris Hani & -38.00 & -77.50 & -47.00 & -43.00 & -56.00 & -40.50 & -40.50 & -43.00 & -24.50 & -37.50 \\
\hline Total & -37.31 & -73.10 & -49.34 & -45.67 & -42.36 & -34.33 & -41.71 & -46.95 & -22.33 & -32.38 \\
\hline DLRC & Q11STD & Q14STD & Q15STD & Q16STD & Q17STD & Q18STD & Q19STD \\
\hline Sarah Baartman & -27.14 & -18.57 & -24.29 & -24.29 & -22.86 & -25.71 & -12.14 & -25.71 \\
\hline Joe Gqabi & -15.36 & -13.57 & -11.07 & -12.50 & -23.57 & & -11.43 \\
\hline Chris Hani & -29.50 & -24.00 & -25.00 & -36.00 & -18.00 & & -17.00 & -18.29 & -18.05 \\
\hline Total & -24.00 & -18.71 & -20.12 & -24.26 & -21.48 & & - \\
\hline
\end{tabular}

The priorities identified through the discrepancy scores for collaboration are, in turn, confirmed by the priority needs of external support, as specifically collected in the survey questionnaire (see Appendix A). Across the three DLRCs in Table 8, the most important areas where support is required, according to the respondents, are the financial (FIN median of five "most important") and human resource bases (HR median of four). The human resources ambition aims especially at setting up a skilled permanent secretariat for the DLRCs. The financial resources should allow travel, accommodation, increased stipends, and project implementation. In addition, some important specific needs arise: to better defend and pursue the common as well as the own group's interests in Sarah Baartman (INTRST 4); the elaboration of legislation and policies with a more substantial input from local stakeholders (LEGPOL) and better power relations (PWR) in Joe Gqabi (twice median of 4); and the interaction between central and local level stakeholders (CNTLOC), especially in Sarah Baartman (4.5) and in Joe Gqabi (4). Other areas, such as physical resources and infrastructure (PIR), information exchange (INFO), leadership (LDR) or norms and values toward shared outcomes (NORM), appear as less of a priority for external intervention and support. It is noteworthy that the most promising DLRC Joe Gqabi also expresses the most urgent need for support in critical areas such as human resources, legal and policy clarity, financial resources, power relations within the DLRC and interaction with central 
level stakeholders. The high responses of commitment and trust from its DLRC members in this survey corroborate the HSRC's [7] earlier assessment, namely that the explanation for this sense of urgency should rather be sought in this particular DLRC's eagerness to move ahead despite the difficult conditions it faces.

Table 8. Priority areas of external support for collaboration as an innovation (median scores).

\begin{tabular}{cccccccccccc}
\hline DLRC & HR & INTRST & PIR & LEGPOL & FIN & INFO & PWR & CNTLOC & LDR & NORM \\
\hline Sarah Baartman & 4 & 4 & 3.5 & 3 & 5 & 3 & 2 & 4.5 & 3 & 1 \\
\hline Joe Gqabi & 4 & - & 3 & 4 & 5 & 3 & 4 & 4 & 2 \\
\hline Chris Hani & 4 & - & 3.5 & 1 & 5 & 1 & 3 & - & 2 \\
\hline Total & 4 & 4 & 3 & 3 & 5 & 2.5 & 3 & 4 & 2 & 1.5 \\
\hline
\end{tabular}

Ranking scores range from 1: least important to 5: most important.

In short, the SI framework developed here allows for a more structured assessment of collaborative governance as an innovation in DLRCs. Using a fairly simplistic logic to describe complex (sub)system relations, information can be easily collected, analyzed, and understood in terms of how collaboration looks now and where stakeholders want it to evolve to, as well as where priority support needs and opportunities are. It does, however, require further refining, which falls beyond the present scope of the study. These refinements pertain especially to the user-friendliness of the scale of assessment; the quantification of the negative effect power imbalances; identification of the most befitting external support strategies and coordination among their suppliers; and better modeling of possible interaction effects in the complex system set-up.

\section{Conclusion: Some Pointers on the Introduction of Collaborative Governance in FFP Land Administration and Management}

The attempt at introducing collaborative governance in DLRCs in South Africa has been analyzed here by means of an elaboration of Klein Woolthuis, Lankhuizen and Gilsing's [29] generic SI failure framework into a SI framework for collaborative governance. Deploying the elaborated framework to three DLRCs in early 2019 reveals that overall, opportunities for collaboration as an innovation to work are assessed fairly highly from within. The opportunities are commonly discerned to be lowest in the subsystem of administration and highest in the subsystem of governance. The analysis of differences between the actual and preferred assessment scores reveals that the financial resource discrepancy is overall the least satisfactory, clocking a difference between actual and preferred scores of 73.10 percent. High discrepancies of almost 50 percent can be observed for the number and quality of human resources as well as information flow to the district level. The least discrepancy is found in members fulfilling their duties, putting in additional efforts, making decisions for the common interest, being able to defend their interests and the role of leadership. These assessments of present opportunities and failures seem to reflect that while some basic conditions for participation and collaboration are quite present, they require a firmer operational, technical, and institutional backup. This is an important lead for the discussion on participation and collaborative governance in FFP and its scaling-up. The analysis of the introduction of collaborative governance as an innovation in DLRCs confirms Ho, Choudhury, Haran and Leshinsky's findings [3] that, when promoting FFP as an innovation in general, and in particular when scaling up the extent and depth of the participation and collaborative governance, the systemic complexities must not be underestimated. In the SI approach, these complexities are seen to emanate from the non-linear processes in which actors interact with many others in a specific societal set-up, with their own idiosyncratic capabilities. The case of the launching of DLRCs without solid technical, operational, institutional, or methodological support demonstrates that FFP does not only need to be a well-supported and -resourced intervention. To paraphrase Barry [33], for FFP as an innovation to be more than a management bumper sticker and to actually suit local circumstances, our study shows that it needs to adopt a systemic perspective from the 
beginning. A systemic perspective simultaneously pays attention to the various technical (e.g., flexible data capturing, scalability, reliability, time- and resource efficiency) and social dimensions (e.g., tenure regimes, participation, decentralized collaborative governance), as they are conceived to be interlinked elements of a complex FFP land administration system.

Funding: The information gathered for this research was a spin-off in a bilateral development cooperation programme between the Government of Belgium and the Government of South Africa. The personal research activity did not receive any specific additional funding.

Institutional Review Board Statement: Ethical review and approval were waived for this study, as this information gathering was part of a bilateral development cooperation programme.

Informed Consent Statement: Informed consent was obtained from all subjects involved in the study.

Data Availability Statement: Data were not published, but are available in Excel format upon request.

Conflicts of Interest: The authors declare no conflict of interest.

Appendix A. SI Framework for Collaborative Governance Survey Questionnaire

DLRC:

Interview: ... $\ldots \ldots \ldots \ldots \ldots$

Date:

Research project: ASSESSMENT BY DLRC MEMBERS OF OPPORTUNITIES FOR COLLABORATION IN 3 DLRCS

Q: In which capacity or function do you participate in the DLRC?

\section{A: DLRC MEMBER (FUNCTION):}

We will present you with 19 characteristics of

DLRCS which may contribute to successful collaboration among DLRC members. We ask you to assess, how far in your experience and opinion these characteristics:

1. Contribute at present to promote collaboration among the DLRC members?

2. Need to be improved in the future to have a satisfactory collaboration among the DLRC members?

You can score your assessment out of a maximum of $100 \%$, each time in categories from $0-10 \%$ (=around $10 \%)$; $11-20 \%$ (=around $20 \%$ ); $21-30 \%$ (=around $30 \%) ; 31-40 \%$ (=around $40 \%) ; 41-50 \%$ (=around $50 \%) ; 51-60 \%$ (=around $60 \%) ; 61-70 \%$ (= around $70 \%) ; 71-80 \%$ (=around $80 \%$ ); $81-90 \%$ (=around $90 \%$ ); $91-100 \%$ (= $100 \%)$

We will first have three imaginary examples of such an assessment before we start with the real questions.

Example 1: Imagine you and your neighbor share a borehole which dries up regularly without any major disputes. We might ask how far you are able to get along because of clear agreements on how much water you can each pump up every day (e.g., 70\%). How much you would like this water situation to improve?

Example 2: Imagine your boss and you have out-of-office meetings every 6 months to discuss your respective marriages, since your boss believes this will improve your work relationship. You have an actual score of about 50\% (2 times per year); but what does your preferred score looks like?

Wrap up question: If you are asked to score your agreement to a statement, and the 'no agreement at all'- score is $0 \%$, 'do not agree nor disagree'- score is $50 \%$ and 'agree fully' is $100 \%$, then what would be your score for:

1. 'agree to a certain extent': $60 \%, 70 \%$ or $80 \%$ i

2. agree mostly': $70 \%, 80 \%$ or $90 \%$ ?

Actual: $\% 70$

Preferred: $\%$.....

Actual: $\% 50$

Preferred: \%...... 
1. Physical resources and infrastructure to fulfil administrative and secretarial functions of DLRC: meeting venue and facilities; IT equipment; stationary, etc.

Actual: \%

Preferred: \%

2. Financial resources to run the operations of DLRC: e.g., sitting allowances, travel allowances, resources for site visits, payment of support staff; running costs of Secretariat, etc.

Actual: \%

Preferred: \%

3. Number of DRDLR staff and/or members of DLRC who provide operational or technical support to DLRC

Actual: \%

Preferred: \%

4. Efficiency and knowledge of DRDLR staff and/or members of DLRC who provide operational or technical support to DLRC

Actual: \%

Preferred: \%

5. The legally binding laws and legal regulations on DLRC tasks, functions and matters are well known to DLRC members

Actual: \%

Preferred: \%

6. The operational guidelines, policies and strategies outlining the role and functions of DLRCs are well known to DLRC members

Actual: \%

Preferred: \%

7. Information on DLRC matters is usually circulated and exchanged between stakeholders at the local as well as the central level

Actual: \%

Preferred: \%

8. Information on DLRC matters is more circulated among stakeholders at national or provincial level than at district level

Actual: \%

Preferred: \%

9. Members of DLRC find it important to make decisions which promote interests and objectives shared by all members.

Actual: \%

Preferred: \%

10. Members of DLRC exchange questions, ideas and proposals with other stakeholders than DLRC members.

Actual: \%

Preferred: \%

11. Members of DLRC exchange such questions, ideas and proposals mostly only among themselves.

Actual: \%

Preferred: \%

12. In the past-before they joined the DLRC - members of DLRC haveworked well together with each other.

Actual: \%

13. Members of DLRC have very unequal levels of actual power andinfluence when it comes to decision making in the DLRC.

Actual: \%

14. The leadership of the DLRC acts and supports the decision making in the DLRC in such a manner that members of DLRC are able to come to shared, joint decisions.

Actual: \%

Preferred: \%

15. All members of the DLRC are able to defend their own interests and of those groups they represent in the DLRC's process of decision making.

Actual: \%

Preferred: \%

16. All members of the DLRC defend the common interests of all people of the district 
17. All members of the DLRC do fulfil the duties they are legally obliged to fulfil.

18. All members of the DLRC willingly do extra tasks in addition to their standard duties when they are asked to do.

19. All members of the DLRC take the initiative to fulfil additional tasks in addition to their standard duties (going the extra mile).
Actual: \%

Preferred: \%

Actual: \%

Preferred: \%

Actual: \%

Preferred: \%

20. We discussed in this research factors which according to collaboration theory can improve trust and collaboration between committee members, such as the human resources available to the DLRCs, the ability of DLRC members to defend and pursue the common as well as their own group's interest, physical resources and infrastructure, legal and policies framework, financial resources, the information exchange and power relations between DLRC members and between central and local level stakeholders, the role of leadership, the existence of norms and values towards shared outcomes, and the will to provide more than only the minimum standard tasks.

If governments or organizations from outside South Africa were willing to assist the DLRCS to improve their operations in land administration and management in line with South Africa's legislation and policies, which of these collaboration areas would you see as the five most important ones for such external support in your DLRC? Please list these five most important areas and explain briefly each time what such external support should consist of, and

for how long it is required (short = 1-2 years; medium: next 5 years; long term: next 10 years).

Finally, order them from least (= score 1) to most important one (= score 5). (Mark the rank in the circle)

o

o

o

o

o
Next 1-2 years

Next 5 years

Next 10 years

(scrap what is not applicable)

Next 1-2 years

Next 5 years

Next 10 years

(scrap what is not applicable)

Next 1-2 years

Next 5 years

Next 10 years

(scrap what is not applicable)

Next 1-2 years

Next 5 years

Next 10 years

(scrap what is not applicable)

Next 1-2 years

Next 5 years

Next 10 years

(scrap what is not applicable) 


\section{References}

1. Enemark, S.; McLaren, R.; Lemmen, C. Fit-For-Purpose Land Administration Guiding Principles; Global Land Tool Network: Nairobi, Kenya, 2016.

2. Enemark, S.; Bell, K.C.; Lemmen, C.; McLaren, R. Fit-For-Purpose Land; World Bank/International Federation of Surveyors (FIG): Copenhagen, Denmark, 2014.

3. Ho, S.; Choudhury, P.R.; Leshinsky, R.; Haran, N. Decentralization as a Strategy to Scale Fit-for-Purpose Land Administration: An Indian Perspective on Institutional Challenges. Land 2021, 10, 199. [CrossRef]

4. Bruce, J. Decentralization of Land Administration in Sub-Saharan Africa: Recent Experiences and Lessons Learned. In Agricultural Land Redistribution and Land Administration in Sub-Saharan Africa: Case Studies of Recent Reforms; The World Bank: Washington, DC, USA, 2014; pp. 55-80.

5. Ibrahim, A.S.; Akanbang, B.A.A.; Laube, W. Sustaining decentralized collaborative governance arrangements in Africa: A case study of land management committees in the Upper West Region, Ghana. GeoJournal 2020. [CrossRef]

6. GoSA. District Land Reform Committees (DLRCS) Draft Policy Framework. Version 30; Department of Rural Development and Land Reform (DRDLR): Pretoria, South Africa, 2015.

7. HSRC. Land Use and Needs Assessment District Land Reform Committee (DLRC) Research Capacity Building Pilot Project; Final Report; Human Sciences Research Council for DRDLR-Belgian Technical Cooperation (BTC): Pretoria, South Africa, 2017.

8. Walker, C. The Limits to Land Reform: Rethinking 'The Land Question'. J. South. Afr. Stud. 2005, 31, 805-824. [CrossRef]

9. GoSA (Government of South Africa). White Paper on Reconstruction and Development, Notice 1954 of 1994. 23 November; Parliament: Cape Town, South Africa, 1994.

10. GoSA. White Paper on South African Land Policy; Department of Land Affairs: Pretoria, South Africa, 1997.

11. GoSA. Statistics on Settled Restitution Claims Cumulative Statistics: 1995-31 December 2016 (CRLR) and on Land Delivery per Province Cumulative Data; DRDLR: Pretoria, South Africa, 2017.

12. GoSA. Department of Rural Development \& Land Reform Strategic Plan 2010-2013; Department of Rural Development \& Land Reform: Pretoria, South Africa, 2010.

13. GoSA. The Comprehensive Rural Development Programme Framework. Version 1, July; Ministry of Rural Development and Land Reform: Pretoria, South Africa, 2009.

14. GoSA. National Development 2030. In Our future-Make it Work; National Planning-The Presidency: Pretoria, South Africa, 2012.

15. PSC (Public Service Commission). An Evaluation of Integration and Coordination in the Integrated Sustainable Rural Development Programme; Public Service Commission: Pretoria, South Africa, 2009.

16. Akpan, W. Local knowledge, global knowledge, development knowledge: Finding a new balance in the knowledge power play. S. Afr. Rev. Sociol. 2011, 42, 116-127. [CrossRef]

17. GoSA. Constitution of the Republic of South Africa No. 108 of 1996; Parliament: Cape Town, South Africa, 1996.

18. Claassens, A. Law, Land and Custom, 1913-2014: What Is at Stake Today. In Land Divided, Land Restored. Land Reform in South Africa for the 21st Century; Cousins, B., Walker, C., Eds.; Jacana: Auckland Park, New Zealand, 2015; pp. 68-84.

19. Siddle, A.; Thomas, K. The Failure of Decentralisation in South African Local Government. Complexity and Unanticipated Consequences; UCT Press: Claremont, CA, USA, 2012.

20. GoSA. Green Paper on Land Reform; Department of Rural Development and Land Reform: Pretoria, South Africa, 2011.

21. Waeterloos, E. State-led agrarian reform in South Africa: Policy incoherencies and the concern for authoritarian populism. Can. J. Dev. Stud. 2020, 41, 399-416. [CrossRef]

22. GoSA. National Policy for Beneficiary Selection and Land Allocation; Draft Version 9 November 2019; No. 42939; Government Gazette: Hong Kong, China, 2020; pp. 23-54.

23. Lægreid, P.; Randma-Liiv, T.; Rykkja, L.; Sarapuu, K. The Governance of Social Cohesion: Innovative Coordination Practices in Public Management; Cocops Work Package 5-Deliverable 5.3; Department of Public Administration: Hong Kong, China, 2013.

24. Thomson, A.; Perry, J. Collaboration Processes: Inside the Black Box. Public Adm. Rev. 2006, 66, 20-32. [CrossRef]

25. Emerson, K.; Nabatchi, T.; Balogh, S. An Integrative Framework for Collaborative Governance. J. Public Adm. Res. Theory 2012, 22, 1-29. [CrossRef]

26. Ansell, C.; Gash, A. Collaborative Governance in Theory and Practice. J. Public Adm. Res. Theory 2007, 18, 543-571. [CrossRef]

27. Charbitt, C. Governance of Public Policies in Decentralised Contexts: The Multi-Level Approach; OECD Regional Development Working Papers; No. 2011/04; OECD: Paris, France, 2011.

28. Edquist, C. System of Innovation Approaches-Their Emergence and Characteristics. In Systems of Innovation. Technologies; Institutions and Organizations: London, UK, 1997; pp. 1-35.

29. Woolthuis, R.K.; Lankhuizen, M.; Gilsing, V. A system failure framework for innovation policy design. Technovation 2005, 25, 609-619. [CrossRef]

30. Varblane, U.; Tamm, D. The Development of the Systemic Approach to Innovation. In Innovation in Small Catching-Up Economies; New Perspectives on Practice and Policy; Springer: New York, NY, USA, 2012; pp. 3-19.

31. Teisman, G.; Klijn, E. Complexity Theory and Public Management. Public Manag. Rev. 2008, 10, 287-297. [CrossRef]

32. Morçöl, G. A Complexity Theory for Public Policy; Routledge: London, UK, 2012; p. 303.

33. Barry, M. Fit-for-purpose land administration-Administration that suits local circumstances or management bumper sticker? Surv. Rev. 2018, 50, 383-385. [CrossRef] 